American J. of Engineering and Applied Sciences 2 (4): 635-642, 2009

ISSN 1941-7020

(C) 2009 Science Publications

\title{
Efficient Detection Algorithm for a Multiple-Input and Multiple-Output Multiuser Multi-Carrier Code Division Multiple Access in Time-Varying Channels
}

\author{
Fares Sayadi, Mahamod Ismail, Norbahiah Misran, Kasmiran Jumari and Mardina Abdullah \\ Department of Electrical, Electronic and Systems Engineering, \\ Faculty of Engineering and Built Environment, National University of Malaysia, \\ 43600 University Kebangsaan Malaysia Bangi Selangor Darul Ehsan, Malaysia
}

\begin{abstract}
Problem statement: Maximum Likelihood (ML) decoding has been applied for the uplink of a Multi-Carrier Code Division Multiple Access (MC-CDMA) system based on Orthogonal Frequency Division Multiplexing (OFDM). Multiple-Input Multiple-Output (MIMO) channel from k users, which moves at vehicular speed, to the Base-Station (BS) is time-varying. For time-varying channels, Sphere Decoding (SD) was introduced to perform ML decoding. Whereas, computational complexity of SD (due to a QR-factorization for each symbol), is nevertheless high. Modified SD had been proposed to achieve near optimum solutions that called Subspace-Sphere Decoder (SPSD). Approach: Proposed algorithm was based on subspace and orthogonal projection with very small dimensionality as robustness scheme in an iterative Multi-User Detection (MUD) and Parallel Interference Cancelation (PIC) method. Results: This approach had been achieved intense reduction of computational complexity for time-varying channel via one and more than one order of magnitude at channel estimation and multiuser detection respectively. Furthermore, SPSD was robustness to channel estimation error (about $3.8 \mathrm{~dB}$ ) as compared to the representative counterparts in literature. Conclusion: Effectiveness of proposed method was demonstrated by simulations.
\end{abstract}

Key words: Sphere decoding method, orthogonal projection, low complexity receiver, time variant channel, Multiple-Input Multiple-Output (MIMO), Multi-Carrier Code Division Multiple Access (MC-CDMA)

\section{INTRODUCTION}

We consider the uplink of a Multi-Carrier CodeDivision Multiple Access (MC-CDMA) system based on Orthogonal Frequency Division Multiplexing (OFDM) with $\mathrm{N}$ subcarriers. We focus on A MultipleInput Multiple-Output (MIMO) multi-user system. Each user $\mathrm{k} \in\{1, \ldots, \mathrm{K}\}$, has $\mathrm{T}$ transmitted antennas and the base-station provides with $\mathrm{R}$ receive antennas. The receiver carries out iterative Parallel Interference Cancelation (PIC), channel estimation and Multi-User Detection (MUD) jointly ${ }^{[1-3]}$. For multi-user detection a subspace-based sphere decoder is employed.

$\operatorname{In}^{[3]}$, the researchers use the Sphere Decoding (SD) in an iterative receiver for each user independently after PIC is more robust to channel estimation errors than a Linear Minimum Mean Square Error (LMMSE) filter. For time-varying channels the computational complexity of the SD in ${ }^{[3]}$, due to a QR-factorization for each symbol, is nevertheless high.

Contribution of the paper: We model the time-varying channel developing a SD method. Our model allows improving a novel implementation of the classical SD technique for time-varying channels by advantage of Discrete Prolate Spheroidal (DPS) sequences. Our new algorithm allows intense reduction of computational complexity. In this study, the time-variant channel model utilizing the subspace and orthogonal projection via DPS sequences and the proposed detection algorithm are detailed as well as the computational complexity.

System model: An iterative multi-user MIMO receiver for a MC-CDMA uplink, executing PIC followed by $\mathrm{SD}$, related $\mathrm{to}^{[2-4]}$, as well as channel model are presented. We define the transmit antenna $t \in\{1, \ldots, \mathrm{T}\}$ of user $\mathrm{k} \in 1, \ldots \mathrm{K}$ ) using the indexing $(\mathrm{k}, \mathrm{t})$.

Corresponding Author: Fares Sayadi, Department of Electrical, Electronic and Systems Engineering, Faculty of Engineering and Built Environment, National University of Malaysia, 43600 UKM Bangi Selangor Darul Ehsan, Malaysia 


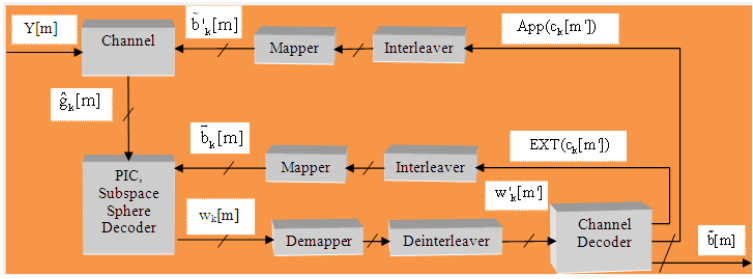

Fig. 1: Illustration of the iterative MC-CDMA receiver

Multi-antenna transmitter: Let us consider the transmitter of user $\mathrm{k} \in\{1, \ldots \mathrm{K}\}$ whereas each transmit antenna $(k, t)$ with $t \in\{1, \ldots T\}$ sends a block of $M$ OFDM symbols, including 1 pilot symbols affording for channel estimation. (M-J)T data symbols are jointly coded, interleaved, mapped to a QPSK constellation and split into $\mathrm{T}$ blocks of length (M-J). Data symbol $\mathrm{b}(\mathrm{k}, \mathrm{t})$ is spread over all $\mathrm{N}$ subcarriers using $\mathrm{i}, \mathrm{i}, \mathrm{d}$ spreading sequence $\mathrm{s}_{(\mathrm{k}, \mathrm{t})} \in{ }_{\mathrm{C}}{ }^{\mathrm{N}}$ from a QPSK constellation. Thus, transmit antenna $(k, t)$ sends the OFDM symbols $\mathrm{s}_{(\mathrm{k}, \mathrm{t})} \mathrm{b}_{(\mathrm{k}, \mathrm{t})}[\mathrm{m}]$ for:

$\mathrm{m} \in\{\{0, \ldots, \mathrm{M}-1\}-\{$ pilot positionsin each data black $\}\}$

Iterative multi-antenna receiver: The iterative receiver structure as shown in Fig. 1. The propagation channel from transmit antenna $(k, t)$ to receive antenna $r$ is characterized by the frequency response $\operatorname{gr}_{(k, t)}[\mathrm{m}] \in \mathbb{C}^{\mathrm{N}}$ at time instant $\mathrm{m}$ with elements $\mathrm{gr}_{(\mathrm{k}, \mathrm{t})}[\mathrm{m}$, q]. The index $q \in\{0, \ldots, N-1\}$ denotes the subcarrier index. The related effective spreading sequence is defined by:

$\tilde{\mathrm{s}}_{\mathrm{r}(\mathrm{k}, \mathrm{t})}=\operatorname{diag}\left(\mathrm{g}_{\mathrm{r}(\mathrm{k}, \mathrm{t})}[\mathrm{m}]\right) \mathrm{s}(\mathrm{k}, \mathrm{t})$

In the following, we will omit the time index $\mathrm{m}$ unless necessary, the contribution of transmit antenna $(k, t)$ to the signal at receive antenna $r$ is $\tilde{s}_{r,(k, t)} b_{(k, t)}$. The received signals from all transmit antennas of all users at the receive antenna $\mathrm{r}$, can be expressed as follows:

$\mathrm{y}_{\mathrm{r}}=\sum_{\mathrm{k}=1}^{\mathrm{K}} \sum_{\mathrm{t}=1}^{\mathrm{T}} \tilde{\mathrm{s}} \tilde{\mathrm{r}}_{(\mathrm{k}, \mathrm{t})} \mathrm{b}_{(\mathrm{k}, \mathrm{t})}+\mathrm{n}_{\mathrm{r}}$

This can be expressed in matrix notation as:

$\mathrm{y}_{\mathrm{r}}=\tilde{\mathrm{s}}_{\mathrm{r}} \mathrm{b}+\mathrm{n}_{\mathrm{r}}$

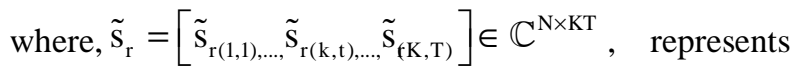
the effective spreading matrix at antenna $r$, $\mathrm{b}=\left[\mathrm{b}_{(\mathrm{l}, 1)}, \ldots, \mathrm{b}_{(\mathrm{k}, \mathrm{t})}, . . \mathrm{b}_{(\mathrm{K}, \mathrm{T})}\right]^{\mathrm{T}} \in \mathbb{C}^{\mathrm{KT}}$ is entail all KT transmitted symbols and $\mathrm{n}_{\mathrm{r}}$ is additive white Gaussian noise with zero mean and variance $\sigma_{z}^{2} \mathrm{I}_{\mathrm{N}}$.
Denoting by $y=\left[y_{1}^{T}, \ldots, y_{R}^{T}\right]^{T}$ the vector containing the $\mathrm{R}$ received signals is now given by:

$\mathrm{y}=\tilde{\mathrm{s}} \mathrm{b}+\mathrm{n}$

where, $\tilde{\mathrm{s}}=\left[\tilde{\mathrm{s}}_{1}^{\mathrm{T}}, \ldots, \tilde{\mathrm{s}}_{\mathrm{R}}^{\mathrm{T}}\right]^{\mathrm{T}} \in \mathbb{C}^{\mathrm{NR} \times \mathrm{KT}}$ represents all $\mathrm{R}$ effective spreading matrices and the noise vector $\mathrm{n}$ has zero mean with variance $\sigma_{\mathrm{z}}^{2} \mathrm{I}_{\mathrm{NR}}$.

The contribution of user $\mathrm{k}$ (i.e., derivation from symbols $b^{(k)}=\left[b_{(k, 1)}, \ldots, b_{(k, 1)}\right]^{T}$ can be expressed as follows:

$\mathrm{Y}^{(\mathrm{k})}=\hat{\mathrm{s}}^{(\mathrm{k})} \mathbf{b}^{(\mathrm{k})}+\mathrm{n}^{(\mathrm{k})}$

Where:

$$
\hat{\mathrm{s}}^{(\mathrm{k})}\left[\begin{array}{ccc}
\tilde{\mathrm{s}}_{1(\mathrm{k}, 1)} & \ldots & \tilde{\mathrm{s}}_{1(\mathrm{k}, \mathrm{T})} \\
\vdots & \tilde{\mathrm{s}}_{\mathrm{r}(\mathrm{k}, \mathrm{t})} & \vdots \\
\tilde{\mathrm{S}}_{\mathrm{R}(\mathrm{k}, 1)} & \cdots & \tilde{\mathrm{s}}_{\mathrm{R}(\mathrm{k}, \mathrm{T})}
\end{array}\right]=\in \mathbb{C}^{\mathrm{NR} \times \mathrm{T}}
$$

is the effective spreading sequences from all transmit antenna of user $\mathrm{k}$ to all receive antennas. To execute detection of the desirable user, removing the contribution of all other users (i.e., $\mathrm{k} \neq \mathrm{k}$ ) in (4), by accomplishing PIC:

$$
\begin{aligned}
\tilde{y}^{(k)}= & -\sum_{k \neq k} y^{\left(k^{\prime}\right)}=y-\sum_{k \neq \neq} \tilde{s}^{\left(k^{(k)}\right)} b^{\left(k^{(}\right)} \\
& \approx y-\tilde{s} \tilde{b}+\tilde{s}^{(k)} \tilde{b}^{(k)} \approx \tilde{s}^{(k)} b^{(k)}+n^{(k)}
\end{aligned}
$$

The soft symbols in $\tilde{b}_{(k, t)}[\mathrm{m}]$ and $\tilde{b}_{(k, t)}[\mathrm{m}]$ are computed from the extrinsic probabilities and A Posteriori Probabilities (APP) respectively, equipped by the BCJR decoder (i.e., the (M-J) T detected symbols $\mathrm{w}_{(\mathrm{k}, t)}[\mathrm{m}]$ are jointly de-mapped, de-interleaved and decoded using a BCJR decoder) ${ }^{[3,5]}$ after detection using:

$$
\begin{aligned}
\tilde{\mathrm{b}}_{(\mathrm{k}, \mathrm{t})}[\mathrm{m}] & =\frac{1}{\sqrt{2}}\left(2 \operatorname{EXT}\left(\mathrm{c}_{(\mathrm{k}, \mathrm{t})}[2 \mathrm{~m}]\right)-1\right) \\
& +\mathrm{j} \frac{1}{\sqrt{2}}\left(2 \operatorname{EXT}\left(\mathrm{c}_{(\mathrm{k}, t)}[2 \mathrm{~m}+1]\right)-1\right)
\end{aligned}
$$

$$
\begin{aligned}
\tilde{\mathrm{b}}_{(\mathrm{k}, \mathrm{t})}[\mathrm{m}] & =\frac{1}{\sqrt{2}}\left(2 \operatorname{APP}\left(\mathrm{c}_{(\mathrm{k}, \mathrm{t})}[2 \mathrm{~m}]\right)-1\right) \\
& +\mathrm{j} \frac{1}{\sqrt{2}}\left(2 \operatorname{APP}\left(\mathrm{c}_{(\mathrm{k}, \mathrm{t})}[2 \mathrm{~m}+1]\right)-1\right)
\end{aligned}
$$

To perform MUD entangles PIC (7) for user k, we combine the subspace SD algorithm in order to detect $b^{(k)}$ by an appropriate iterative structure to reduce the computational complexity. 
Time-variant channel model: The estimating of timevariant frequency response $\mathrm{gr}_{(\mathrm{k}, \mathrm{t})}[\mathrm{m}]$ demonstrates performance of the iterative receiver structure since the effective spreading sequence $\tilde{\mathrm{s}}_{\mathrm{r}(\mathrm{k}, \mathrm{t})}$ truthfully depends on the factual channel realization.

The maximum variation in time of the wireless channel is upper-bounded by maximizing normalized one-sided Doppler bandwidth ${ }^{[4]}$ :

$$
\mathrm{V}_{\mathrm{D} \max }=\frac{\mathrm{vmax} \mathrm{fc}_{\mathrm{c}}}{\mathrm{C}_{\mathrm{o}}} \mathrm{T}_{\mathrm{s}}
$$

Where:

$$
\begin{aligned}
& \mathrm{v}_{\text {Dmax }}=\text { The maximum (supported) velocity } \\
& \mathrm{T}_{\mathrm{s}}=\text { The OFDM symbol duration } \\
& \mathrm{f}_{\mathrm{c}} \quad=\text { The carrier frequency } \\
& \mathrm{c}_{\mathrm{o}} \quad=\text { The speed of light }
\end{aligned}
$$

Time-limited snapshots of the band-limited fading process span a subspace with very small dimensionality. The same subspace is spanned by Discrete Prolate Spheroidal (DPS) sequences ${ }^{[4]}\left\{\mathrm{u}_{\mathrm{i}}[\mathrm{m}]\right\}$ are defined $a^{[6]}$ :

$$
\lambda_{\mathrm{i}} \mathrm{u}_{\mathrm{i}}[\mathrm{m}]=\sum_{\mathrm{l}=0}^{\mathrm{M}-1} \frac{\sin \left(2 \pi \mathrm{v}_{\mathrm{D} \max }(1-\mathrm{m})\right.}{\pi(1-\mathrm{m})} \mathrm{u}_{\mathrm{i}}[1]
$$

The sequences $\left[\mathrm{u}_{\mathrm{i}}[\mathrm{m}]\right\}$ are doubly orthogonal over the infinite set $\{-\propto, \ldots, \propto\}$ and the finite set $\mathrm{J}_{\mathrm{M}}=\{0, \ldots, \mathrm{M}-1\}$, band-limited by $\operatorname{vDmax}$ and maximally energy concentrated on $\mathrm{J}_{\mathrm{M}}$. The Slepian basis function $\mathrm{u}_{\mathrm{i}}=\left(\mathrm{u}_{\mathrm{i}}[\mathrm{m}]\right)_{\mathrm{m} \in\{0, \ldots, \mathrm{M}-1)}$ is the time-limited DSP sequences. The eigenvalue $\lambda_{\mathrm{i}}$ are primped such that $\lambda_{1}>\lambda_{2}, \ldots>\lambda$, the time-variant frequency selective channel $\mathrm{g}_{\mathrm{r}(\mathrm{k}, \mathrm{t})}[\mathrm{m}] \in \mathrm{C}^{\mathrm{N}}$ for the duration of a single data block $\mathrm{J}_{\mathrm{M}}=\{0, \ldots \mathrm{M}-1\}$ is projected onto the subspace spanned by linear superposition of the first D Slepian sequences and is approximated as:

$$
\begin{aligned}
\mathrm{g}_{\mathrm{r}(\mathrm{k}, \mathrm{t})}[\mathrm{m}] \approx \hat{\mathrm{g}}_{\mathrm{r}(\mathrm{k}, \mathrm{t})}[\mathrm{m}] & =\sum_{\mathrm{i}=1}^{\mathrm{D}} \phi_{\mathrm{r}(\mathrm{k}, \mathrm{t})}[\mathrm{i}] \mathrm{u}_{\mathrm{i}}[\mathrm{m}] \\
& =\Phi_{\mathrm{r}(\mathrm{k}, \mathrm{t})} \psi[\mathrm{m}]
\end{aligned}
$$

where, the matrix $\Phi_{\mathrm{r}(k, t)} \in \mathbb{C}^{\mathrm{N} \times \mathrm{D}}$ contains all the subcarrier coefficients for every subcarrier $q \in\{0, \ldots, N$ $1\}$ and the vector $\psi[\mathrm{m}]=\left[\left[\mathrm{u}_{1}[\mathrm{~m}], \ldots \mathrm{u}_{\mathrm{D}}[\mathrm{m}]\right]^{\mathrm{T}} \in \mathbb{C}^{\mathrm{D}}\right.$ for $\mathrm{m} \in(0, \ldots \mathrm{M}-1)$. The dimension $\mathrm{D}$ is order of 3-5 for practical issues ${ }^{[2,4]}$. Substituting (12) into (1) yields:

$\tilde{\mathrm{s}}_{\mathrm{r}(\mathrm{k}, \mathrm{t})}=\operatorname{diag}\left(\Phi_{\mathrm{r}(\mathrm{k}, \mathrm{t})} \psi[\mathrm{m}]\right) \mathrm{s}(\mathrm{k}, \mathrm{t})$

And substituting (13) into (6) can be expressed as $\hat{\mathrm{s}}^{(\mathrm{k})}=\widehat{\Phi}^{(\mathrm{k})} \dot{\psi}[\mathrm{m}]$, where:

$$
\begin{aligned}
\widehat{\Phi}^{(k)} & =\left[\begin{array}{ccc}
\operatorname{diag}\left(\Phi_{2(k 2)}\right) \mathrm{s}(\mathrm{k}, 1) & \cdots & \operatorname{diag}\left(\Phi_{2(k, t)}\right) \mathrm{s}(\mathrm{k}, \mathrm{T}) \\
\vdots & \ddots & \vdots \\
\operatorname{diag}\left(\Phi_{\mathrm{R}(\mathrm{k} 2)}\right) \mathrm{s}(\mathrm{k}, 1) & \cdots & \operatorname{diag}\left(\Phi_{2(\mathrm{k}, \mathrm{t})}\right) \mathrm{s}(\mathrm{k}, \mathrm{T})
\end{array}\right] \\
& \in \mathbb{C}^{\mathrm{NR} \times \mathrm{DT}}
\end{aligned}
$$

and

$\dot{\psi}[\mathrm{m}]=\left[\begin{array}{ccc}\psi[\mathrm{m}] & 0 & 0 \\ 0 & \ddots & 0 \\ 0 & 0 & \psi[\mathrm{m}]\end{array}\right] \in \mathbb{C}^{\mathrm{DT} \times \mathrm{T}}$

Consequently, the received signal of user $\mathrm{k}$ after PIC given in (7) can be represented as:

$\tilde{\mathrm{y}}^{(\mathrm{k})}[\mathrm{m}]=\bar{\Phi}^{(\mathrm{k})} \psi[\mathrm{m}] \mathrm{b}^{(\mathrm{k})}[\mathrm{m}]+\mathrm{n}^{(\mathrm{k})}[\mathrm{m}]$

The sphere decoder is developed by context of above equation.

Sphere decoder and its modifications: The SD technique was introduced in $^{[7]}$ to perform the Maximum Likelihood (ML) decoding by searching over only those points of the lattice that lie within a hypersphere of radius $\mathrm{p}$ around the received signal ${ }^{[8,9]}$. Firstly, the ML detection and its low computational complexity implementation using SD are recalled as described in $^{[8]}$. Secondly, utilizing the SD for MUD in the iterative MIMO multiuser MC-CDMA uplink as mentioned above. Then, we exploit the details of the subspace SD structure by using the model (15) to reduce the computational complexity for a MIMO MC-CDMA system.

\section{MATERIALS AND METHODS}

Maximum likelihood decoder: For convenience, we omit the user index $\mathrm{k}$ and superscripts, replaced $\mathrm{s}$ with $\mathrm{H}$ in Eq. 7. The resulting signal model of a MIMO single-user system in a flat-fading channel is given by:

$\mathrm{y}=\mathrm{Hb}+\mathrm{n}$

Suppose there are $\mathrm{T}$ transmit and $\mathrm{R}$ receive antennas. Denote by $b \in \mathbb{C}^{\mathrm{T}}$ and $y \in \mathbb{C}^{\mathrm{R}}$ are the symbol transmitted and the received signal, respectively. Let $\mathrm{H} \in \mathbb{C}^{\mathrm{R} \times T}$ represent the channel matrix and $\mathrm{n} \in \mathbb{C}^{\mathrm{R}}$ is additive complex white Gaussian noise with zero mean and variance $\sigma_{z}^{2} I_{R}$. Indeed, components of the data vector $b^{(t)}$ (here, $t \in\{1, \ldots, T\}$ indexes the layer) are assumed zero-mean, statistically independent with unit variance and are uniformly drawn from the same symbol alphabet $A=\left\{\mathrm{a}_{0}, \ldots, \mathrm{a}_{|\mathrm{A}|-1}\right\}$. All quantities involved in (16) are either real or complex valued. In the complex-valued case, the noise components are assumed as circularly symmetric complex Gaussian. 
The ML detection finds the data symbol vector $b$ in the discrete alphabet $\mathrm{A}^{\mathrm{T}}$ such that maximizes the likelihood function as follows:

$$
b_{m i}=\widehat{b}=\arg \max _{b \in A^{T}} f(y \| b)=\arg \min _{b \in A^{T}}\{\|y-H b\| 2\}
$$

To identify the ML vector, an exhaustive search is required. Due to the number of candidate vectors for $b$ and search over $\mathrm{A}^{\mathrm{T}}$ elements, the complexity increases exponentially with $\mathrm{T}$ We attempt to find a subset of $b$, with small number of candidate vectors, in which the ML vector can be found with a low computational complexity by a SD as following.

The sphere decoder algorithm: The SD have been introduced with small number of candidate vectors in order to reduce an exhaustive search in $(17)^{[3,10,11]}$. This is achieved by considering the search into a subset $\mathrm{C}(\mathrm{p})$ defined as:

$$
\mathrm{C}(\mathrm{p})=\left\{\mathrm{b} \in \mathrm{A}^{\mathrm{T}}\|\mathrm{y}-\mathrm{Hb}\|^{2} \leq \mathrm{p}^{2}\right\}
$$

where, $p>0$ is a given radius, the ML vector can be found in $\mathrm{C}(\mathrm{p})$ as the smallest cost:

$$
\widehat{b} \arg \min \left\{\|\mathrm{y}-\mathrm{Hb}\|^{2}\right\}
$$

The SD technique finds $\mathrm{C}(\mathrm{p})$ for a given $\mathrm{p}$ by applying the thin $\mathrm{QR}$ factorization (or, equivalently, Cholessky decomposition of the Gram matrix $\left(\mathrm{G}=\mathrm{H}^{\mathrm{H}}\right.$ $\mathrm{H})$ of the matrix $\mathrm{H}$, is unique as defined $\mathrm{in}^{[12]}$. Hence, we write $\mathrm{H}=\mathrm{QR}$, where $\mathrm{Q} \in \mathbb{C}^{\mathrm{R} \times \mathrm{T}}$ is a unitary matrix and $R \in \mathbb{C}^{\mathrm{T} \times \mathrm{T}}$ is an upper triangular matrix. From Eq. 18, the following constraints can be derived:

$$
\|\mathrm{z}-\mathrm{Rb}\|^{2} \leq \mathrm{p}^{2}
$$

where, $\mathrm{z}=\mathrm{Q}^{\mathrm{H}} \mathrm{y}$, the error vector to be minimized is given by $\in=\mathrm{z}-\mathrm{Rb}$.

For $\mathrm{t} \in\{1, \ldots, \mathrm{T}\}$, define the partial vectors and the partial matrix as follows:

$$
\begin{aligned}
\mathrm{z}^{(\mathrm{t})} & =\left[[\mathrm{z}[\mathrm{t}], \ldots, \mathrm{z}[\mathrm{R}]]^{\mathrm{T}}\right. \\
\mathrm{b}^{(\mathrm{t})} & =\left[[\mathrm{z}[\mathrm{t}], \ldots, \mathrm{z}[\mathrm{R}]]^{\mathrm{T}}\right. \\
\epsilon^{(\mathrm{t})} & =[\in[\mathrm{t}], \ldots, \in[\mathrm{R}]]^{\mathrm{T}} \\
\mathbf{R}^{(\mathrm{t})} & {\left[\begin{array}{ccc}
\mathrm{R}_{\mathrm{t}, \mathrm{t}} & \ldots & \mathrm{R}_{\mathrm{t}, \mathrm{T}} \\
0 & \ddots & \vdots \\
0 & 0 & \mathrm{R}_{\mathrm{T}, \mathrm{T}}
\end{array}\right] \in \mathbb{C}^{(\mathrm{T}-\mathrm{t}+\mathrm{t}) \times(\mathrm{T}-\mathrm{t}+\mathrm{t})} }
\end{aligned}
$$

Noting that $\mathrm{R}$ is upper-triangular and $\epsilon^{(\mathrm{t})}$ can be written as:
$\epsilon^{(\mathrm{t})}=\mathrm{z}^{(\mathrm{t})}-\mathrm{R}^{(\mathrm{t})} \mathrm{b}^{(\mathrm{t})}$

and substituting (23) into (20) can be expressed as:

$$
\mathrm{d}(\mathrm{t})^{2}=\left\|\epsilon^{(\mathrm{t})}\right\|^{2}=\sum_{\mathrm{i}=\mathrm{t}}^{\mathrm{T}}\|\in[\mathrm{i}]\|^{2}=\mathrm{d}(\mathrm{t}+1)^{2}+\mid \in[\mathrm{t}] \|^{2}
$$

where, $\mathrm{d}(\mathrm{t})$ is the partial distance, meaning that $\mathrm{d}(1)^{2}>\mathrm{d}(2)^{2}>\ldots>\mathrm{d}(\mathrm{t})^{2}$. We denote the set of candidate symbols at step $\mathrm{t}$, with partial distance $\mathrm{d}(\mathrm{t}) \leq \mathrm{p}$, by $\mathrm{C}_{\mathrm{t}}(\mathrm{p})$. The $\mathrm{C}_{\mathrm{t}}(\mathrm{p})$ can be found by backward recursion using (24), for an iterative implementation of SD. Note that if $\mathrm{C}_{\mathrm{t}}(\mathrm{p})$ becomes an empty, there is no vector in $\mathrm{C}(\mathrm{p})$, a larger value of $p$ has to be chosen (if $p \rightarrow \propto$, i.e., over the whole set $\mathrm{A}^{\mathrm{t}}$ ) and the procedure has to be repeated. In this case, we have $C_{t}(p)=A^{T-t+1 .}$ Then, an exhaustive search may be directed to find the ML vector with $C(p)$ Hence, to verify $\mathrm{C}_{1}(\mathrm{p})$ restrain at least the ZF-criterion given by:

$$
\mathrm{b}_{\mathrm{zF}}=\arg \min _{\mathrm{b} \in \mathrm{A}^{\prime}}\left\{\left\|\mathrm{R}^{-1} \mathrm{z}-\mathrm{b}\right\|^{2}\right\}
$$

Consequently, the Eq. 20 becomes $p^{2}=\left\|z-b_{z F}\right\|^{2}$. As soon as we obtain $t$ such that $d(t)^{2}>p^{2}$ (inferring $\left.\mathrm{d}(1)^{2}>\mathrm{p}^{2}\right)$, we abandon all $\mathrm{b} \in \mathrm{A}^{\mathrm{T}}$ having the partial $\mathrm{b}^{(\mathrm{t})}$ $=A^{T-t+1}$ If $C_{t}(p)$ is not empty, we can build $C(p)$ from $\mathrm{C}_{\mathrm{t}}(\mathrm{p}), \mathrm{t} \in\{1, \ldots, \mathrm{T}\}$, as follows:

$\mathrm{C}(\mathrm{p})=\mathrm{C}_{1}(\mathrm{p}) \times \mathrm{C}_{2}(\mathrm{p}) \times \ldots \times \mathrm{C}_{\mathrm{T}}(\mathrm{p})$

where, $\times$ denotes the Cartesian product. After $\mathrm{T}$ steps the SD algorithm terminates. This technique can be demonstrated by tree-pruning in $^{[3,8]}$. The distinct steps of the SD are shown in Table 1. For time-varying channels the computational complexity of the SD due to a QR-factorization for each symbol, is nevertheless high. Hence, we develop a lessened-rank lowcomplexity by using the Eq. 15 and its individual properties, for time-variant channels based on subspace and orthogonal projection with very small dimensionality. The main results of this study are based on the modified subspace-sphere method.

Subspace-sphere decoder combined with thin QR decomposition: the proposed algorithm is considered as an efficient detection algorithm for time-variant channel to reduce the computational complexity. That is a combination of the SD, with a subset of a vector space which employs the PIC at the iterative receiver scheme. We note that $\bar{\Phi}^{(\mathrm{k})}$ and $\psi[\mathrm{m}]$ in (15), are time-invariant despite user dependent and time-variant during common to all users, respectively. Let us now specialize the results as mentioned above to the case of the time-variant channels with thin QR decomposition in Eq. 15, without lose of generality, we omit the superscript $\mathrm{k}$ and $\tilde{\mathrm{y}}^{(\mathrm{k})}[\mathrm{m}]$ rewritten as: 
Am. J. Engg. \& Applied Sci., 2 (4): 635-642, 2009

$\tilde{y}[\mathrm{~m}]=\widehat{\Phi} \psi[\mathrm{m}] \mathrm{b}[\mathrm{m}]+\mathrm{n}[\mathrm{m}]$

Using sorted $\mathrm{QR}$ decomposition of $\bar{\Phi}$, we can write $\widehat{\Phi}=\mathrm{QR}$, where $\mathrm{Q} \in \mathbb{C}^{\mathrm{NR} \times \mathrm{DT}}$ and $\mathrm{R} \in \mathbb{C}^{\mathrm{DT} \times \mathrm{DT}}$ are a unitary matrix and an upper triangular matrix, respectively. Following the same steps as the ML decoder and the SD detection, Eq. 27 and 17, can be expressed as:

$z[m]=Q^{H} \tilde{y}[m]=R \psi[m] b[m]+Q^{H} n[m]$

$\widehat{b}=\arg \min _{b \in A^{\mathrm{T}}}\left\{\|\mathrm{z}[\mathrm{m}]-\mathrm{R} \psi[\mathrm{m}] \mathrm{b}[\mathrm{m}]\|^{2}\right\}$

From Eq. 29, the following SD constraints can be derived:

$$
\|\mathrm{z}[\mathrm{m}]-\mathrm{R} \Psi[\mathrm{m}] \mathrm{b}[\mathrm{m}]\|^{2} \leq \mathrm{p}^{2}
$$

The error vector to be minimized is given by $\epsilon=\mathrm{z}[\mathrm{m}]-\mathrm{R} \dot{\psi}[\mathrm{m}] \mathrm{b}[\mathrm{m}]$. Hence, we revise the Eq. 1-3, 21 and 22 as follows:

$$
\begin{aligned}
\mathrm{z}^{(\mathrm{t})} & =[\mathrm{z}[\mathrm{Dt}-1)+1], \ldots, \mathrm{z}[\mathrm{DT}]]^{\mathrm{T}} \in \mathbb{C}^{\mathrm{D}(\mathrm{T}-\mathrm{t}+1)} \\
\mathrm{b}^{(\mathrm{t})} & =[\mathrm{b}[\mathrm{t}], \ldots, \mathrm{b}[\mathrm{T}]]^{\mathrm{T}} \in \mathbb{C}^{\mathrm{T}-\mathrm{t}+1} \\
\epsilon^{(\mathrm{t})} & =[\in[\mathrm{D}(\mathrm{t}-1)+1], \ldots, \in[\mathrm{DT}]]^{\mathrm{T}} \in \mathbb{C}^{\mathrm{D}(\mathrm{T}-\mathrm{t}+1)} \\
\mathrm{R}^{(\mathrm{t})} & =\left[\begin{array}{ccc}
\mathrm{R}_{\mathrm{t}, \mathrm{t}} & \cdots & \mathrm{R}_{\mathrm{t}, \mathrm{T}} \\
0 & \ddots & \vdots \\
0 & 0 & \mathrm{R}_{\mathrm{T}, \mathrm{T}}
\end{array}\right] \in \mathbb{C}^{\mathrm{D}(\mathrm{T}-\mathrm{t}-1) \times \mathrm{D}(\mathrm{T}-\mathrm{t}+1}
\end{aligned}
$$

Noting that $R^{(t)}$ is upper triangular whose main diagonal elements are upper-triangular and elsewhere are full and Eq. 14 becomes as:

$$
\dot{\psi}^{(t)}=\left[\begin{array}{lll}
\psi[\mathrm{m}] & 0 & 0 \\
0 & \ddots & 0 \\
0 & 0 & \psi[\mathrm{m}]
\end{array}\right] \in \mathbb{C}^{\mathrm{D}(\mathrm{T}-\mathrm{t}-\mathrm{l}) \times \mathrm{D}(\mathrm{T}-\mathrm{t}+1}
$$

Then $\epsilon^{(t)}$ can be written as $\epsilon^{(t)}=z^{(t)}-R^{(t)} \dot{\psi}^{(t)} b^{(t)}$, the partial distance can be expressed as:

$$
\begin{aligned}
\mathrm{d}(\mathrm{t})^{2} & =\left\|\epsilon^{(\mathrm{t})}\right\|^{2}=\left\|\mathrm{z}^{(\mathrm{t})}-\mathrm{R}^{(\mathrm{t})} \boldsymbol{\Psi}^{(\mathrm{t})} \mathrm{b}^{(\mathrm{t})}\right\|^{2} \\
& =\sum_{\mathrm{i}=\mathrm{t}}^{\mathrm{T}} \sum_{\mathrm{j} \in \mathbb{C}^{\mathrm{D}}}|\epsilon[\mathrm{i}, \mathrm{j}]|^{2}=\mathrm{d}(\mathrm{t}+1)^{2}+|\in[\mathrm{t}]|^{2}
\end{aligned}
$$

Let us now drive the subsets of the vector space $\mathrm{z}^{(\mathrm{t})}$ and the elements of $R^{(t)}$, we obtain:

$$
\begin{aligned}
& \widehat{\mathrm{Z}}^{(\mathrm{t})}=\left[\mathrm{z}_{\mathrm{D}(\mathrm{t}-1)+1, \ldots,} \mathrm{Z}_{\mathrm{Dt}}\right]^{\mathrm{T}} \in \mathbb{C}^{\mathrm{D}} \\
& \widehat{\mathrm{R}}^{(\mathrm{t})}=\left[\mathrm{R}_{\mathrm{t}, \mathrm{t}}, \ldots, \mathrm{R}_{\mathrm{tT}}\right] \in \mathbb{C}^{\mathrm{D} \times \mathrm{D}(\mathrm{t}+1)}
\end{aligned}
$$

Table 1: The T steps of the SD algorithm ${ }^{[3]}$

\begin{tabular}{ll}
\hline Step T: & For all $\mathrm{b}[\mathrm{T}] \in \mathrm{A}$ compute $\mathrm{d}(\mathrm{T})^{2}$ If $\mathrm{d}(\mathrm{T})^{2} \leq \rho^{2}$ \\
$\vdots$ & store $\mathrm{b}[\mathrm{T}] \in \mathrm{C}_{\mathrm{t}}(\rho)$ \\
Step $\tau:$ & For all $[\mathrm{b}[\mathrm{t}+1], \ldots \mathrm{b}[\mathrm{t}]]^{\tau} \in \mathrm{C}_{\mathrm{t}+1}(\rho)$ with $\mathrm{b}[\mathrm{t}] \in \mathrm{A}$ \\
& compute $\mathrm{d}(\mathrm{t})^{2}$ \\
& If $\mathrm{d}(\mathrm{T})^{2} \leq \rho^{2} \therefore$ store $[\mathrm{b}[\mathrm{t}], \ldots \mathrm{b}[\mathrm{T}]]^{\tau} \in \mathrm{C}_{\mathrm{t}}(\rho)$ \\
Step 1: & For all $[\mathrm{b}[2], \ldots \mathrm{b}[\mathrm{T}]]^{\tau} \in \mathrm{C}_{\mathrm{z}}(\rho)$ with $\mathrm{b}[1] \in \mathrm{A}$ \\
& compute $\mathrm{d}(1)^{2}$ \\
& If $\mathrm{d}^{2}(1)^{2} \leq \rho^{2}$ store $[\mathrm{b}[1], \ldots \mathrm{b}[\mathrm{T}]]^{\mathrm{T}} \in \mathrm{C}_{2}(\rho)$ \\
\hline
\end{tabular}

Accordingly, the partial distance defined by (33) has now the form:

$$
\begin{aligned}
\mathrm{d}(\mathrm{t})^{2} & =\left\|\epsilon^{(\mathrm{t})}\right\|^{2}=\sum_{\mathrm{i}=\mathrm{t}}^{\mathrm{T}} \sum_{\mathrm{j} \in \mathbb{C}^{\mathrm{D}}}|\in[\mathrm{i}, \mathrm{j}]|^{2}=\sum_{\mathrm{i}=\mathrm{t}}^{\mathrm{T}}\left\|\hat{\mathrm{z}}^{(\mathrm{i})}-\widehat{\mathrm{R}}^{(\mathrm{i})} \tilde{\psi}^{(\mathrm{i})} \mathrm{b}^{(\mathrm{i})}\right\|^{2} \\
& =\mathrm{d}(\mathrm{t}+1)^{2}+|\in[\mathrm{t}]|^{2}
\end{aligned}
$$

Consequently, in order to commit the iterative Subspace-Sphere Decoder (SPSD) algorithm, the d(1) ${ }^{2}$ can be found by backward recursion and initiating at $\mathrm{t}=\mathrm{T}$, using (35) with applying above counterpart's revise in Table 1. The following, we compute complexity of our algorithm in terms of floating point operation (flop).

Computational complexity: Let us here define the computational complexity of the various algorithms. That will be assessed in terms of the required number, as floating point operations (flops) ${ }^{[12]}$. A flop is an addition, subtraction, multiplication, division or square root operation in the real domain. Thus, one Complex Multiplication (CM) requires four real multiplications and two additions, leading to six flops. Similarly, one Complex Addition (CA) requires two flops. In our appointing, the crucial parameters are $\mathrm{T}$ and $\mathrm{R}$ (i.e., the size of system model), $Q=|\mathrm{A}|$ (i.e., the cardinality of the symbol alphabet $A$ ) and $p_{t}=\left|C_{t}(p)\right|$ (i.e., the number of candidate vectors preserved at step $t \in\{1, \ldots, T\})$.

Complexity of the comprehensive search: We demonstrate the advantage of the QR decomposition by evaluating the computational complexity for comprehensive (i.e., exhaustive) search subsequent to QR decomposition as ${ }^{[3]}$ :

$\mathrm{In}^{[12]}$, one QR Decomposition (QRD) of size $\mathrm{NR} \times \mathrm{T}$, possesses complexity as:

$$
\mathrm{C}_{\mathrm{QRD}}=\left(4(\mathrm{NR})^{2}-2 \mathrm{NRT}+\frac{2 \mathrm{~T}^{2}}{3}\right) \text { flops }
$$

Utilizing Comprehensive Search (CS) on the full matrix $\mathrm{H} \in \mathbb{C}^{\mathrm{R} \times \mathrm{T}}$, Without $\mathrm{QR}$ factorization, for all 
possible vectors $b \in A^{T}$, the computation of $\mathrm{Hb}$ requires $\mathrm{NR} \times \mathrm{T} \mathrm{CM}$ and $\mathrm{NR} \times(\mathrm{T}-1) \mathrm{CA}$, proceeding to:

$$
\mathrm{C}_{\mathrm{cs}}^{\mathrm{noORD}}=\mathrm{NR}(8 \mathrm{~T}-2) \mathrm{Q}^{\mathrm{T}} \text { flops }
$$

Applying comprehensive search after a QR decomposition: In this situation, for all possible vectors $b \in A^{T}$, the computation of $R b$ requires (here, $\left.\mathrm{R} \in \mathbb{C}^{\mathrm{T} \times \mathrm{T}}\right)$, exclusively $\frac{\mathrm{T}(\mathrm{T}+1)}{2} \mathrm{CM}$ and $\frac{\mathrm{T}(\mathrm{T}+1)}{2} \mathrm{CA}$, proceeding to $\mathrm{C}_{\mathrm{RD}}=2 \mathrm{~T}(2 \mathrm{~T}+1) \mathrm{Q}^{\mathrm{T}}$ flops . Hence,

$$
\begin{aligned}
\mathrm{C}_{\mathrm{CS}}^{\mathrm{RD}}= & \mathrm{C}_{\mathrm{QRD}}+\mathrm{C}_{\mathrm{Rb}}=\mathrm{T}\left(4(\mathrm{NR})^{2}-2 \mathrm{NRT}+\frac{2 \mathrm{~T}^{2}}{3}\right. \\
& \left.+(4 \mathrm{~T}+2) \mathrm{Q}^{\mathrm{T}}\right) \text { flops }
\end{aligned}
$$

Complexity of the sphere decoder: Using the SD algorithm which is illustrated in Table 1, we can now elaborate on the computational complexity utilizing an iterative implementation of the sphere decoder method by refining the derivations $\mathrm{in}^{[3]}$. We define the cardinality preserved at step $t$ such that $\mathrm{p}_{\mathrm{t}}=\left|\mathrm{C}_{\mathrm{t}(\mathrm{p})}\right|=\mathrm{Q}^{\mathrm{T}-\mathrm{t}+1}$.

We consider the computation at step $\mathrm{t}$ and time instant $\mathrm{m}$ (i.e., $\mathbf{R}^{(\mathrm{t})} \mathbf{b}^{(\mathrm{t})}$ ) as follows:

- For all $[b[t+1], \ldots b[T]]^{\mathrm{T}} \in \mathrm{C}_{t+1}(\mathrm{p})$, the computation requires (T-t) $\mathrm{CM}$ and (T-t-1) $\mathrm{CA}$

- For all $\mathrm{b}[\mathrm{t}] \in \mathrm{A}$, the computation requires only one $\mathrm{CM}$ and one $\mathrm{CA}$

Therefore:

$\mathrm{C}_{\mathrm{SD}}=8 \mathrm{TQ}+2 \sum_{\mathrm{m}} \sum_{\mathrm{t}=1}^{\mathrm{T}-1} \mathrm{p}_{\mathrm{t}+1}(4 \mathrm{~T}-4 \mathrm{t} 1)$ flops

The Total Complexity Order (TCO), for data block of length M-J, to account with Eq. 36, can be obtained a:

$\mathrm{C}_{\mathrm{SD}}^{\mathrm{TCO}}=\mathrm{C}_{\mathrm{SD}}+(\mathrm{m}-\mathrm{j}) \mathrm{C}_{\mathrm{QRD}}$

To compute an upper-bound of Eq. 40, we can substitute $\mathrm{p}_{\mathrm{t}+1}$ with $\mathrm{Q}^{\mathrm{T}-\mathrm{t}}$ in Eq. 39 as follows:

$\mathrm{C}_{\mathrm{SD}}^{\mathrm{TCO}}=\operatorname{SUM}\left(\mathrm{C}_{\mathrm{SDsc}}+(\mathrm{M}-\mathrm{J}) \mathrm{C}_{\mathrm{QRD}}\right.$

Complexity of the subspace-sphere decoder: To evaluate the performance of our proposed detection method (SPSD), the computation at step $\mathrm{t}$ and time instant $\mathrm{m}$ (i.e., $\widehat{\mathrm{R}}^{(t)} \tilde{\psi}^{(t)} b^{(t)}$ ) can be acquired as follows:

- The computation of $\dot{\psi}^{(t)} b^{(t)}$ requires, $D(T-t) C M$ and D CM for all $[\mathrm{b}[\mathrm{t}+1], \ldots \mathrm{b}[\mathrm{T}]]^{\mathrm{T}} \in \mathrm{C}_{\mathrm{t}+1}(\mathrm{p})$ and for all $\mathrm{b}[\mathrm{t}] \in \mathrm{A}$, respectively
- The computation of $\hat{\mathrm{R}}^{(\mathrm{t})} \tilde{\mathrm{\psi}}^{(t)} \mathrm{b}^{(\mathrm{t})}$ requires $\mathrm{D}^{2}[\mathrm{~T}-\mathrm{t}-$ 1) $+\mathrm{D}(\mathrm{D}+1) / 2 \mathrm{CM}$ and $\mathrm{D}^{2}[\mathrm{~T}-\mathrm{t}-1)+\mathrm{D}(\mathrm{D}-1) / 2 \mathrm{CA}$ for all $[\mathrm{b}[\mathrm{t}+1], \ldots \mathrm{b}[\mathrm{T}]]^{\mathrm{T}} \in \mathrm{C}_{\mathrm{t}+1}(\mathrm{p})$ in addition $\left.\mathrm{D}[\mathrm{D}+1)\right) / 2$ $\mathrm{CM}$ and $\mathrm{D}[\mathrm{D}-1)) / 2 \mathrm{CA}$ for all $\mathrm{b}[\mathrm{t}] \in \mathrm{A}$

- $\quad$ One QRD of size NR $\times$ DT, possesses complexity as:

$$
\mathrm{C}_{\mathrm{QRD}}=\mathrm{DT}\left(4(\mathrm{NR})^{2}-2 \mathrm{DNRT}+\frac{2(\mathrm{DT})^{2}}{3}\right) \text { flops }
$$

Hence:

$$
\begin{aligned}
\mathrm{C}_{\mathrm{SPSD}}= & 4 \mathrm{D}(2+\mathrm{D}) \mathrm{TQ}+2 \mathrm{D} \\
& \sum_{\mathrm{m}} \sum_{\mathrm{t}=1}^{\mathrm{T}-1} \mathrm{p}_{\mathrm{t}+1}(1+\mathrm{D}=4 \mathrm{D})(\mathrm{T}-\mathrm{t}) \text { flops }
\end{aligned}
$$

The TCO concerning SPSD, can be obtained as:

$$
\mathrm{C}_{\mathrm{SPSD}}^{\mathrm{TCO}}=\mathrm{C}_{\mathrm{SPSD}}+\mathrm{C}_{\mathrm{QRD}}
$$

where, (M-J) is the data block length and $\mathrm{C}_{\mathrm{QRD}}$ is demonstrated in Eq. 42.

Consequently, we compute an upper-bound of Eq. 43 as same as Eq. 41 as follows:

$\mathrm{C}_{\mathrm{SPSDSc}}^{\mathrm{TCO}}=\mathrm{C}_{\mathrm{SPSDsc}}+\mathrm{C}_{\mathrm{QRD}}$

\section{RESULTS}

Simulation setup: We use the same simulation setup as $\mathrm{in}^{[1,3]}$. The realizations of the time-variant frequency selective fading channel $h_{r(k, t)}[n, l]$, sampled at the chip rate $R_{c}=1 / T_{c}$ are generated utilizing an exponentially decaying power delay profile as:

$$
\eta^{2}[1]=\mathrm{e}^{-1 / 4} \sum_{1^{1}}^{\mathrm{L}-1} \mathrm{e}^{\mathrm{1}^{\mathrm{p}} / 4}
$$

With root mean square (rms) delay spread $\mathrm{T}_{\mathrm{D}}=4 \mathrm{~T}_{\mathrm{c}}$ $\cong 1 \mu$ s for a chip rate of $\mathrm{R}_{\mathrm{c}}=3.84 .10^{6} \mathrm{~Hz}^{[14,15]}$. The autocorrelation for every channel tap is given by Clarke spectrum (e.g., resolvable paths, $\mathrm{L}=15$ ). The system operates at carrier frequency $f_{c}=2 \mathrm{GHz}$ and $k \in\{16,24$, $32,64\}$, users move with velocity $\mathrm{v}=102.5 \mathrm{~km} \mathrm{~h}^{-1}$. According to mentioned parameters the Doppler bandwidth is, $B_{D} \cong 190 \mathrm{~Hz}$. The number of subcarriers is $\mathrm{N}=64$ and the OFDM symbol with cyclic prefix has length $\mathrm{P}=\mathrm{N}+\mathrm{G}=79$. The data block comprise of $\mathrm{M}=256$ OFDM symbols as well as $1=60$ pilot symbols which results in a $\mathrm{D} \geq\left[2 \mathrm{v}_{\operatorname{Dmax}} \mathrm{M}\right]+1 \cong 3$. Due to investigate the diversity gain of the receiver only (i.e., no antenna gain) the MIMO channel taps are normalized as ${ }^{[13]}$ :

$$
\mathrm{E}\left\{\sum_{\mathrm{t}=1}^{\mathrm{T}} \sum_{\mathrm{r}=1}^{\mathrm{R}} \sum_{\mathrm{l}=0}^{\mathrm{L}}\left\|\mathrm{h}_{\mathrm{r}(k, \mathrm{t})}[\mathrm{n}, 1]\right\|^{2}\right\}=1
$$


All depicted results are averaged over 100 independent channel realizations by applying the data transmission as a QPSK constellation ${ }^{[16]}$. Without loss of generality, we can assume each user applying equal number of transmitter and receiver antenna (i.e., $\mathrm{T}=\mathrm{R}$ ).

\section{DISCUSSION}

To evaluate the proposed method, simulations are performed in tree steps.

The bit error rate performance: Firstly, we compared the results in terms of Bit-Error-Rate (BER) versus SNR. We focus on the multiuser detector utilizes the subspace-sphere method. In Fig. 2 we illustrate the BER versus $E_{b} / N_{o}$ for different users as well as in fully loaded systems (i.e., $\mathrm{k}=\mathrm{N}=64$ ). The solid lines demonstrate the results for Perfect Channel knowledge (PC), while the dashed lines show the results for subspace-sphere Channel Estimates (CE). We also depict the Single User Bound (SUB), which indicates the BER that is achieved with one single user and assuming that the receiver has access to the exact channel knowledge (i.e., coefficients). We compare our results with ${ }^{[3]}$, as the following:

- With exact knowledge of the channel: LMMSE, sphere decoder and subspace-sphere multiuser detector exhibit to perform, respectively

- Utilizing channel estimates, the subspace-sphere method adjacent to sphere decoder for identical iteration. Subspace-sphere detection outperforms LMMSE detection, which is stouter to channel estimation error (about $3.8 \mathrm{~dB}$ )

The QR decomposition computational complexity: Secondly, we show the advantage of the QRD in term of flops. For instance, suppose $\mathrm{T}=\mathrm{R}=4$, the Eq. 37 and 38 becomes as:

$$
\begin{aligned}
& \mathrm{C}_{\mathrm{CS}}^{\mathrm{noQRD}} \cong 1.97 \cdot 10^{6} \text { flops } \\
& \mathrm{C}_{\mathrm{CS}}^{\mathrm{QRD}} \cong 1.06 .10^{6} \text { flops }
\end{aligned}
$$

Hence, the ratio $\mathrm{y}=\mathrm{C}_{\mathrm{CS}}^{\mathrm{QRD}} / \mathrm{C}_{\mathrm{CS}}^{\mathrm{noORD}} \cong 53.8 \%$, we see that when executing a QRD first and subsequently comprehensive search, which permits complexity reduction of a factor approximately 1.85 .

The global computational complexity: At the final step, we compared the computational complexity based on the number of flops required with other representative counterparts ${ }^{[3,13]}$. In Table 2, to exhibit an easy reference from our derivations, we comparison the analytic expressions for the total numbers of complex multiplications, additions required by the aforementioned methods.

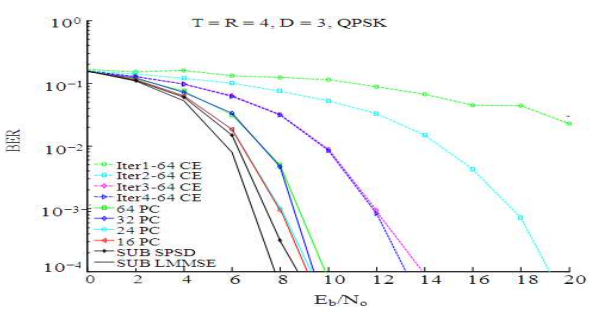

Fig. 2: BER Vs SNR with $k \in 16,24,32,64\}$ users for SPSD method

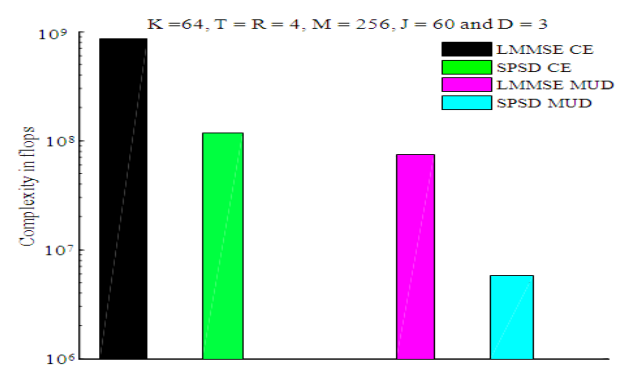

Fig. 3: Computational complexity in flops: For Channel Estimation (CE) and multiuser detection (MUD)

Table 2: Comparison of computational complexity

Detectors Complex multiplications/additions

LMMSE $^{[13]} \quad 2 \mathrm{~T}^{2}\left(\mathrm{~K}^{2} \mathrm{~T} / 3+8 \mathrm{~N} \mathrm{KT}+\mathrm{N}-\mathrm{K}\right)(\mathrm{M}-\mathrm{J})$

$\left.\mathrm{SD}^{[3]} \quad\left[2 \mathrm{~T}^{3}\left(2 \mathrm{~N}^{2}-\mathrm{N}+1 / 3\right)+\mathrm{T}(8 \mathrm{Q}+2)+4 \sum_{\mathrm{t}=1}^{\mathrm{T}} \mathrm{p}_{\mathrm{t}+1}\right)\right](\mathrm{M}-\mathrm{J})$

SD $\quad$ as well as above $\left.-\left(2 \mathrm{~T}+6 \sum_{\mathrm{t}=1}^{\mathrm{T}-1} \mathrm{p}_{\mathrm{t}+1}\right)\right](\mathrm{M}-\mathrm{J})$

$2 \mathrm{~T}^{3}\left(2 \mathrm{~N}^{2}-\mathrm{N} / \mathrm{D}+1 /\left(3 \mathrm{D}^{2}\right)\right) / \mathrm{D}+[2 \mathrm{D}$

PSD $\left.\left.\quad(4+2 \mathrm{D}) \mathrm{TQ}+\sum_{\mathrm{t}=1}^{\mathrm{T}-\mathrm{t}} \mathrm{p}_{\mathrm{t}+1}(1+\mathrm{D}+(3+4 \mathrm{D})(\mathrm{T}-\mathrm{t}))\right](\mathrm{M}-\mathrm{J})\right)$

We show the computational complexity in Fig. 3 for $\mathrm{k}=64, \mathrm{~T}=\mathrm{R}=4, \mathrm{M}=256, \mathrm{~J}=60$ and $\mathrm{D}=3$ as acquired from simulations, per receiver iteration. The subspace-sphere method authorizes a complexity reduction of approximate one order of magnitude for channel estimation by implementing four iterations. Utilizing the subspace-sphere multiuser decoder for joint antenna detection with PIC leads to computational complexity reduction by more than one order of magnitude. This complexity reduction comes at the expenditure of a slight increase of BER (about 0.58 $\mathrm{dB})$. Consequently, a trade-off has to be made between performance and computational complexity, which is sufficient for practical and macroeconomic issues.

\section{CONCLUSION}

We have presented the subspace method applying sphere detection as an alternative to the LMMSE and classical sphere decoder for MIMO multicarrier CDMA systems. The subspace-sphere algorithm is proposed to joint time-varying channel estimation and multiuser 
detection. To achieve high accuracy, we have been combined the subspace-sphere method with interference cancelation for every stage. We also defined suitable radius of searching termination. In this study, a low computational complexity receiver performing Soft Input Soft Output (SISO) channel decoder with BCJR algorithm are studied by a hybrid method that involves the extrinsic information for the multiuser computation and the APP for the channel estimation in context of additional pilot symbols. Our new method allows drastic computational complexity reduction one and more than one order of magnitude at the channel estimation and the multiuser detection respectively, that is validated by simulation results. Applying the subspace-sphere methods implies a slight loss in performance which is insignificant compared to the gain in computational complexity.

\section{ACKNOWLEDGMENT}

The researchers deeply indebted to Institute of Space Science (ANGKASA) UKM, UKM Gran: LL02-FRGS0002-2007, for sponsoring this research.

\section{REFERENCES}

1. Mecklenbräuker, C.F., J. Wehinger, T. Zemen, H. Artés and F. Hlawatsch, 2006. Multiuser MIMO Channel Equalization. In: Smart Antennas-State-of-the-Art, Ser. EURASIP Book Series on Signal Processing and Communications, Kaiser, T., A. Bourdoux, H. Boche, J.R. Fonollosa, J.B. Andersen and W. Utschick (Eds.). Hindawi, New York, USA., ISBN: 13: 978-9775945099, pp: 53-76.

2. Zemen, T., C.F. Mecklenbräuker, J. Wehinger and R.R. Müller, 2006. Iterative joint time-variant channel estimation and multi-user detection for MC-CDMA. IEEE. Trans. Wireless Commun., 5: 1469-1478.

http://cat.inist.fr/?aModele $=$ afficheN\&cpsidt $=17921098$

3. Dumard, C. and T. Zemen, 2007. Sphere decoder for a MIMO multi-user MC-CDMA uplink in timevarying channels. Proceeding 17th IEEE International Conference on Communications, June 2428, Glasgow, Scotland, pp: 2580-2585. DOI: 10.1109/ICC.2007.427

4. Zemen, T. and C.F. Mecklenbräuker, 2005. Timevariant channel estimation using discrete prolate spheroidal sequences. IEEE Trans. Signal Proc., 53: $3597-3607$.

http://cat.inist.fr/?aModele $=$ afficheN\&cpsidt $=17032729$

5. Bahl, L.R., J. Cocke, F. Jelinek and J. Raviv, 1974. Optimal decoding of linear codes for minimizing symbol error rate. IEEE Trans. Inform. Theor., 20: 284-287.
6. Slepian, 1978. Prolate spheroidal wave functions, Fourier analysis and uncertainty-V: The discrete case. Bell Syst. Technol. J., 57: 1371-1430.

7. Viterbo and J. Boutros, 1999. A universal lattice code decoder for fading channels. IEEE Trans. Inform. Theor., 45: 1639-1642. http://adsabs.harvard.edu/abs/1978ATTTJ..57.1371S

8. Burg, A., M. Borgmann, M. Wenk, M. Zellweger, W. Ficht-ner and H. Bölcskei, 2005. VLSI implementation of MIMO detection using the sphere decoding algorithm. IEEE J. Solid-State Circ., 40: 1566-1577. DOI: 10.1109/JSSC.2005.847505

9. Damen, M.O., H.E. Gamal and G. Caire, 2003. On maximum-likelihood detection and the search for the closest lattice point. IEEE Trans. Inform. Theor., 49: 2389-2402. DOI: 10.1109/TIT.2003.817444

10. Schnorr, C.P. and M. Euchner, 1994. Lattice basis reduction: Improved practical algorithms and solving subset sum problems. Math. Prog., 66: 181-199. DOI: $10.1007 / \mathrm{BF} 01581144$

11. Fincke, U. and M. Pohst, 1985. Improved methods for calculating vectors of short length in a lattice, including a complexity analysis. Math. Comput., 44: 463-471. http://www.citeulike.org/user/puja/article/2878876

12. Golub, G.H. and C.F.V. Loan, 1996. Matrix Computations. 3rd Edn., Baltimore (MD), Johns Hopkins University Press, USA., ISBN: 0801854148, pp: 694.

13. Dumard, C. and T. Zemen, 2006. Krylov subspace method based low-complexity mimo multi-user receiver for time-variant channels. Presented at the 17th IEEE International Symposium on Personal, Indoor, Mobile Radio Communication, Sept. 1114, Helsinki, Finland, pp: 1-5. DOI: 10.1109/PIMRC.2006.254009

14. Clarke, R.H., 1968. A statistical theory of mobileradio reception. Bell Syst. Technol. J., 47: 957-1000. http://citeseer.comp.nus.edu.sg/context/193925/0

15. Correia, L.M., 2001. Wireless Flexible Personalized Communications. Wiley, New York, ISBN: 047149836X, pp: 482.

16. Hanzo, L., T.H. Liew and B.L. Yeap, 2002. Turbo Coding, Turbo Equalization and Space-Time Coding for Transmission over Fading Channels. Wiley Blackwell Publishing, USA., ISBN: 10: 0470847263, pp: 766. 